\title{
Tuberculous ureteric stricture
}

\section{A M Abeygunasekara ${ }^{1}, \mathbf{S}$ De Silva ${ }^{2}$ and A Gurusingha ${ }^{3}$}

(Index words: Clinical features, ultrasound scan, intravenous urogram, histology)

\section{Abstract}

The management of a young woman with a ureteric stricture is a challenge to the urologist. Genitourinary tuberculosis can cause ureteric strictures, with minimal symptoms. Untreated, it can lead to impairment of renal function. Diagnosis of genitourinary tuberculosis may be delayed until histopathological assessment. Drug treatment and reconstructive surgery produce good results.

\section{Case report}

A 36 year old woman with right loin pain for 8 months was found to have ultrasonic evidence of right hydronephrosis and hydroureter. She had no lower urinary tract symptoms, dysuria or haematuria. The past history was uneventful with no previous personal or family history suggestive of tuberculosis. The physical examination was normal.

An intravenous urogram revealed a poorly functioning hydronephrotic right kidney and a faintly visualised dilated ureter. The left kidney and ureter were normal. At cystoscopy the bladder mucosa appeared normal, but an attempt to pass a ureteric catheter through the right ureteric orifice for retrograde study failed, as there was resistance just beyond the ureteric orifice. Urine analysis was normal and the ESR was $12 \mathrm{~mm}$ in the first hour. Three consecutive early morning samples of urine were negative for acid-fast bacilli. Urine culture for Mycobacterium tuberculosis was also negative. The chest radiograph showed clear lung fields. The tuberculin skin test was positive $(19 \mathrm{~mm})$.

At operation, after excision of the strictured lower part (about $3 \mathrm{~cm}$ long), the ureter was reimplanted directly into the bladder using a non-refluxing extravesical technique. The histopathology of the resected ureteric segment showed caseating granulomas indicative of tuberculosis.

\section{Discussion}

Genitourinary tuberculosis is typically a late manifestation of previous pulmonary infection. It develops in 3 to $5 \%$ cases of pulmonary tuberculosis $(1,2)$. Rarely the primary infection is derived from the gut. Spread via the blood stream results in tuberculosis of the urinary tract. Genitourinary tuberculosis frequently leads to the formation of strictures in the urinary tract $(3,4)$. These may lie within the renal pelvis, in the ureter or more rarely in the prostate gland or urethra. By far the commonest site of obstruction is at or near the lower end of a ureter $(2,5)$. Antegrade spread from a proximal urothelial focus and tuberculous ureteritis cause obliteration of the ureteric lumen by oedema or fibrosis (6).

Genitourinary tuberculosis often produces few symptoms until the bladder is involved. Then most patients develop irritative voiding symptoms and dysuria (1). Macroscopic haematuria and renal pain occur in a minority of patients. Fever, weight loss, anorexia and fatigue are uncommon (2).

Patients with genitourinary tuberculosis will usually have a positive tuberculin skin test (2). Genitourinary tuberculosis causes abnormalities of the intravenous urogram in about $90 \%$ cases (2). Some degree of ureteric hold up and dilation is a common finding on intravenous urography. Inability to pass a ureteric catheter through the obstructed segment is considered definitive evidence of a fibrous stricture (7). A significant proportion of patients are diagnosed at operation.

Antituberculous drug treatment regimens for pulmonary and genitourinary tuberculosis are similar (2). Steroids may also be used in an attempt to reduce fibrosis and prevent stricture formation (8). Somtimes the results are exceptionally good, but more often they are disappointing $(1,5)$. If a fibrous stricture is already present, it is unrealistic to expect much benefit from steroids. Transluminal balloon dilation has been recommended if the stenosis can be negotiated by a guidewire (6). In cases where it is not possible, the obstruction can be relieved only by excision of the stricture and reimplantation of ureter directly into the bladder using a non-refluxing technique (8).

\section{References}

1. Backer LRI. Genitourinary tuberculosis. In Weatherall DJ, Ledingham JGG, Warrell DA, Oxford textbook of medicine. 3rd Ed. Oxford University Press; 1996: 3275-79.

2. Folwer JE. Urinary tract infection and inflammation. Year Book Medical Publications. Chicago, London; 1990: 259-68.

3. Allen FJ, De Kock ML. Genitourinary tuberculosis - experience with 52 urology patients. South African Medical Journal 1993; 83: 903-7.

4. O’Flynn JD. Surgical treatment of genitourinary tuberculosis. British Journal of Urology 1970; 42: 667.

'Urological Surgeon and ${ }^{2,3}$ Senior House Officers, Urology Unit, Teaching Hospital Karapitiya, Galle, Sri Lanka. Corresponding author A M A, email: amabey@sltnet.lk (Accepted 24 March 2001). 


\section{Case reports}

5. Calridge M. Ureteric obstruction in tuberculosis. British Journal of Urology 1970: 42: 688-92.

6. Waller RM, Finnerty DP, Casarella WJ. Transluminal balloon dilation of tuberculous ureteric stricture. Journal of Urology 1983; 129: 1225-6.
7. Rees RWM. The ureter in renal tuberculosis. British Journal of Urology 1970; 42: 693-6.

8. Gow JG, Barbosa S. Genitourinary tuberculosis. A sudy of 1117 cases over a period of 34 years. British Journal of Urology 1986; 56: 449-55. 